\title{
Programa nacional de alimentação escolar: há segurança na produção de alimentos em escolas de Salvador (Bahia)?
}

\author{
National school food program: \\ are the foods produced in the schools \\ of Salvador (Bahia), Brazil, safe?
}

\author{
Ryzia de Cassia Vieira CARDOSO' \\ José Ângelo Wenceslau GÓES ${ }^{1}$ \\ Rogéria Comastri de Castro ALMEIDA ${ }^{1}$ \\ Alaíse Gil GUIMARÃES² \\ Danile Leal BARRETO ${ }^{1}$ \\ Sueli Alves da SILVA ${ }^{1}$ \\ Karla Vila Nova de Araújo FIGUEIREDO \\ Permínio Oliveira VIDAL JÚNIOR \\ Edleuza Oliveira SILVA ${ }^{4}$ \\ Larissa Brito HUTTNER'
}

RES U M O

\section{Objetivo}

Avaliar a segurança da produção de alimentos em escolas atendidas pelo Programa Nacional de Alimentação Escolar, em Salvador (BA).

\section{Métodos}

Realizou-se um estudo transversal, com aplicação de formulários elaborados com base na Resolução de Diretoria Colegiada n²16/04 da Agência Nacional de Vigilância Sanitária/Ministério da Saúde, em amostra estratificada formada por 235 escolas atendidas pelo Programa Nacional de Alimentação Escolar, contemplando a rede estadual e municipal de ensino da cidade de Salvador. No formulário, os itens avaliados apresentavam pontuação diferenciada em função do grau de risco associado à segurança dos alimentos. De acordo com a pontuação

1 Universidade Federal da Bahia, Escola de Nutrição, Departamento de Ciência dos Alimentos. R. Araújo Pinho, 32, Canela,

40110-150, Salvador, BA, Brasil. Correspondência para/Correspondence to R.C.V. CARDOSO. E-mail: <ryzia@ufba.br>.

2 Universidade Federal da Bahia, Faculdade de Farmácia, Departamento de Análises Bromatológicas. Salvador, BA, Brasil.

3 Universidade Federal da Bahia, Faculdade de Farmácia, Curso de Especialização em Segurança e Inspeção de Alimentos.

Salvador, BA, Brasil.

4 Secretaria Municipal de Saúde de Salvador. Salvador, BA, Brasil. 
802 | R.C.V. CARDOSO et al.

obtida, as escolas foram classificadas em cinco grupos em relação à condição higiênico-sanitária: crítico; insatisfatório; regular; bom e excelente.

\section{Resultados}

Na avaliação global de adequação, 57,0\% (134) das unidades apresentaram condições insatisfatórias, 42,6\% (100) regulares e 0,4\% (1) boa. Os itens que mais contribuíram para o baixo desempenho estão relacionados aos seguintes blocos: edificação, instalações, equipamentos, móveis e utensílios; higienização; abastecimento de água; manipuladores de alimentos; preparo dos alimentos e exposição do alimento preparado para consumo. Em condição intermediária de atendimento ficaram os blocos controle integrado de vetores e pragas urbanas, manejo de resíduos e matérias-primas, ingredientes e embalagens.

\section{Conclusão}

Verificou-se elevado nível de não conformidade quanto ao atendimento dos requisitos sanitários vigentes, o que evidencia falhas na segurança da produção da alimentação escolar. Os resultados indicam a necessidade de adoção de medidas corretivas com vistas a reduzir riscos à saúde das crianças assistidas e aumentar a eficiência do Programa Nacional de Alimentação Escolar, no município de Salvador (BA).

Termos de indexação: Alimentação escolar. Higiene dos alimentos. Produção de alimentos. Segurança alimentar e nutricional.

\section{A B S T R A C T}

\section{Objective}

The objective of this study was to assess if the foods prepared in the schools of Salvador, Bahia, that participate in the National School Food Program are safe.

\section{Methods}

A cross-sectional study was done through the administration of forms based on the Resolução de Diretoria Colegiada $n^{\circ} 216 / 04$ of the National Sanitary Surveillance Agency/Ministry of Health to a stratified sample consisting of 235 schools serviced by National School Food Program, which included the state and municipal schools of Salvador. The items assessed by the form were scored according to their risk in terms of food safety. Based on their scores, the schools were then classified into five groups according to their level of hygiene and sanitation: critical, unsatisfactory, satisfactory, good and excellent.

\section{Results}

In the global adequacy assessment, 57\% (134) of the schools presented unsatisfactory hygiene and sanitation levels, $42.6 \%$ (100) presented satisfactory levels and $0.4 \%$ (1) presented good levels. The items that contributed most for the poor performance of many schools were grouped in the following categories: building, facilities, equipment, furniture and appliances, hygiene, piped water supply, food handlers, food preparation and exposed ready-to-eat foods. The groups that had some influence on poor performance were associated with the control of urban vectors and pests, management of wastes and raw materials, ingredients and packages.

\section{Conclusion}

A high level of non-conformity with the current sanitation requirements was verified, evidencing that the preparation of school foods was not entirely safe. The results indicate that corrective measures are necessary to reduce health risks and increase the efficiency of National School Food Program in the city of Salvador.

Indexing terms: School feeding. Food hygiene. Food production. Food security.

\section{N T R O D U Ç Ã O}

Na esfera da educação pública, o direito à alimentação está consagrado na Constituição Federal, Artigo 208, inciso VII, que dispõe que "o dever do Estado com a educação será efetivado mediante a garantia de atendimento ao educando, no ensino fundamental, através de programas suplementares de material didático-escolar, transporte, alimentação e assistência à saúde" 1 .

Implementado em 1955 e considerado um dos maiores programas do mundo na área de 
alimentação escolar, o Programa Nacional de Alimentação Escolar (PNAE) tem como objetivo "atender às necessidades nutricionais dos alunos durante sua permanência em sala de aula, contribuindo para o crescimento, o desenvolvimento, a aprendizagem e o rendimento escolar dos estudantes, bem como a formação de hábitos alimentares saudáveis"2.

O PNAE tem como público definido os pré-escolares e escolares do ensino da rede pública, os alunos de creches públicas e filantrópicas, assim como os de escolas indígenas e quilombolas ${ }^{2}$, com atendimento de cerca de 36 milhões de brasileiros ${ }^{3}$. Considerando que as crianças atendidas por esse programa estão em constante crescimento e fazem parte do grupo de indivíduos mais vulneráveis às Doenças Veiculadas por Alimentos (DVA), é importante avaliar todas as condições em que os alimentos são preparados e distribuídos para que eles cumpram plenamente sua função de nutrir.

Nesse contexto, ainda que a segurança de alimentos em espaços educacionais compreenda tema de interesse em diversos segmentos de ensino e que estejam normatizadas ações com vistas ao controle de qualidade dos alimentos distribuídos pelo PNAE², estudos conduzidos em diferentes estados do país evidenciam instalações, condições e práticas impróprias à produção de alimentos na execução do Programa ${ }^{4-8}$, o que coloca em risco a saúde das crianças assistidas.

A Agência Nacional de Vigilância Sanitária (ANVISA)/Ministério da Saúde, atenta à necessidade de promover maior nível de segurança dos alimentos prontos para o consumo à população brasileira, em setembro de 2004, após consulta pública e consolidação de conteúdo técnico, editou a Resolução de Diretoria Colegiada (RDC) $n^{\circ}$ 216/049 , marco normativo que estabelece o Regulamento Técnico sobre Boas Práticas para Serviços de Alimentação.

Este trabalho teve como objetivo avaliar a segurança na produção de alimentos em escolas atendidas pelo PNAE, em Salvador (BA), com base em requisitos estabelecidos pela referida Resolução.

\section{M É T O D O S}

Trata-se de um estudo transversal conduzido junto a escolas públicas do ensino fundamental da cidade de Salvador (BA), no período de maio a dezembro de 2005, como parte do projeto "Apoio à produção de alimentos seguros em escolas públicas atendidas pelo Programa Nacional de Alimentação Escolar, em Salvador (BA)" (Processo 505733/04-8/CNPq), que conta com aprovação pelo Comitê de Ética em Pesquisa da Maternidade Climério de Oliveira/Universidade Federal da Bahia.

Para formação da amostra foram utilizados dados fornecidos pelas Secretarias de Educação do Município de Salvador e do Estado da Bahia, que apresentavam o registro do universo de escolas da rede estadual (250) e municipal (359). A partir desses dados e considerando o cálculo de amostra estratificada, estabelecidos um valor de alfa de $5 \%$ e uma precisão 0,05 , fizeram parte da amostra 97 unidades escolares estaduais e 139 municipais. Em cada segmento escolar, as unidades foram selecionadas ao acaso, pelo uso de tabela de números aleatórios, observando-se a setorização de áreas organizacionais apresentada pelos dois órgãos.

A avaliação das unidades escolares de produção de alimentos foi realizada por meio da aplicação de um formulário semiestruturado, tipo check-list, elaborado com base na RDC 216/049. O formulário utilizado compreendeu duas categorias de informações, sendo a primeira referente à identificação do serviço e caracterização do seu quadro de funcionários e a segunda relativa ao controle sanitário. Na segunda categoria, de acordo com o conteúdo da RDC 216/04', foram organizados nove blocos, com os seguintes aspectos: 1) Edificação, instalações, equipamentos, móveis e utensílios; 2) Higienização de instalações, equipamentos, móveis e utensílios; 3) Controle integrado de vetores e pragas urbanas; 4) Abastecimento de água; 5) Manejo de resíduos; 6) Manipuladores de alimentos; 7) Matérias-primas, ingredientes e embalagens; 8) Preparo dos alimentos 
e 9) Exposição do alimento preparado para consumo.

O formulário foi aplicado durante visitas de inspeção, com a finalidade de verificar as condições sanitárias das instalações, do armazenamento, da produção, da higiene e da saúde dos manipuladores de alimentos, bem como avaliar se os critérios de segurança na produção dos alimentos eram obedecidos. O preenchimento do instrumento se deu mediante observação local e entrevistas.

As questões relativas ao aspecto sanitário, em função do grau de risco associado à segurança dos alimentos, foram pontuadas diferentemente (peso 1, 2 ou 3). A pontuação final alcançada em cada unidade foi calculada a partir do total de pontos obtidos nas questões em conformidade, dividido pelo total da pontuação possível para total de itens avaliados, sendo subtraído do denominador os pontos referentes às questões para as quais foi admitida a resposta não se aplica (nsa), conforme fórmula abaixo:

$$
\text { Escore obtido (EO) }=\frac{\sum \text { dos pontos positivos }}{\begin{array}{l}
\sum \text { dos pontos possíveis } \\
-\left(\sum \text { dos pontos dos itens não aplicáveis }\right)
\end{array}} \times 100
$$

De acordo com a pontuação obtida, as escolas foram classificadas, em relação à condição higiênico-sanitária, em cinco grupos: crítico, com atendimento inferior a $30 \%$ do total dos itens avaliados; insatisfatório, com atendimento maior ou igual a 30 e menor que 50\%; regular, com atendimento maior ou igual a 50 e menor que $70 \%$; bom, com atendimento maior ou igual a 70 e menor que $90 \%$; e excelente, quando maior ou igual a $90 \%$.

As informações coletadas foram tabuladas para construção de um banco de dados; utilizou o Statistical Package for the Social Sciences, versão 13 (SPSS Inc., Chicago, Estados Unidos), que, além da avaliação de adequação global, analisou, de modo separado e em bloco, as frequências de atendimento das variáveis que compunham a base de dados.

\section{RESULTADOS E DISCUSS ÃO}

Das 236 escolas selecionadas, 235 participaram do estudo. Em uma das unidades da rede municipal, a avaliação foi impossibilitada em virtude de inconsistência nos dados cadastrais da escola e dificuldade de acesso durante o período letivo.

\section{Resultados globais do check-list}

Os resultados de classificação global das escolas (Figura 1) permite caracterizar uma situação de não conformidade para a maior parte das unidades investigadas, sendo extremamente reduzido o número daquelas em melhores condições.

Diferente do perfil encontrado no presente estudo, trabalho conduzido por Piragine ${ }^{10}$, em quarenta escolas da rede estadual de Curitiba (PR), reporta a seguinte classificação: 2,5\% excelentes, $17,5 \%$ muito boas, $52,5 \%$ regulares, 5,0\% deficientes e 2,5\% precárias. Dado o contraste do quadro, pode-se interpretar diferenças significativas na implementação do PNAE no Nordeste e no Sul do País.

De acordo com Daniels et al. ${ }^{11}$, que identificaram 604 surtos de DVA em escolas nos Estados Unidos, entre 1973 a 1997, há necessidade de fortalecer a segurança de alimentos em ambientes escolares com vistas à proteção da saúde dos usuários: uma recomendação que bem se aplica diante dos resultados encontrados nas escolas de Salvador.

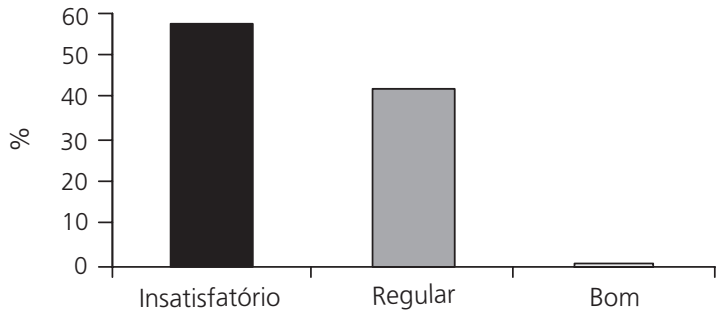

Figura 1. Classificação geral das unidades escolares quanto à adequação aos requisitos sanitários estabelecidos ${ }^{9}$. 


\section{Resultados por blocos de avaliação}

Excetuando-se o bloco referente à matéria-prima, no qual $66,4 \%$ das unidades têm classificação inferior ao limite de 70,0\% de conformidade, em todos os outros blocos, mais de 70,0\% dos casos apresentam distribuição abaixo desse limite, contribuindo marcadamente para o baixo desempenho global (Tabela 1). Os blocos relativos à edificação, água, preparo e exposição dos alimentos e manipuladores destacaram-se como de maior inadequação.

A análise conjunta desses resultados, além de refletir o não atendimento à legislação, revela a possibilidade de riscos à saúde associados a fatores diversos, ao longo das etapas de produção da alimentação escolar. Dessa forma, os fatores contribuem sinergicamente na determinação da qualidade higiênico-sanitária não satisfatória, favorecendo a ocorrência de DVA.

\section{Edificação, instalações, equipamentos, móveis e utensílios}

De acordo com os dados obtidos, em $85,5 \%$ das unidades visitadas, o acesso à área de produção era independente, entretanto, na área externa, notou-se a presença de objetos estranhos, animais e depósitos de lixo. Identificou-se situação ainda mais grave nas áreas internas, onde $73,6 \%$ das cantinas continham objetos estranhos ao ambiente e em 2,1\% observou-se a presença de animais: fatores que propiciam o estabelecimento e a propagação de vetores e pragas assim como a disseminação de doenças.
Entre as unidades, observou-se que $96,6 \%$ não apresentavam áreas distintas para o preparo de alimentos, $77,0 \%$ não tinham teto liso, lavável e impermeável, 76,6\% não contavam com portas ajustadas ao batente e $96,2 \%$ não possuíam proteção das aberturas por tela milimétrica.

Em estudo realizado por Silva et al. ${ }^{4}$, na rede estadual de ensino na cidade de São Paulo (SP), verificou-se que $12,5 \%$ das escolas não apresentavam telas de proteção na área de preparo, permitindo a entrada de insetos. Em 42,7\% dos casos, foram observados pombos no momento da distribuição da alimentação escolar, fato que foi atribuído à falta de portas na área de distribuição.

Nas escolas investigadas em Salvador, constatou-se que a iluminação era adequada em $90,2 \%$ das cantinas, entretanto verificou-se ausência de proteção luminária em sua maioria (96,6\%). Em mais de $25 \%$ das cantinas, as instalações elétricas não eram embutidas, o que contribui para o acúmulo de sujidades, além de constituírem condição de risco ao trabalhador e ao patrimônio público.

$\mathrm{Na}$ área de produção da alimentação escolar, 50,2\% das escolas não apresentavam fluxo linear e unidirecional de operações em virtude da limitação de espaço e de adaptações na instalação das cantinas, o que dificulta procedimentos de higienização e de manutenção de equipamentos e pode contribuir para a ocorrência de contaminação cruzada.

A condição de fluxo não linear também foi descrita para cantinas de escolas dos estados

Tabela 1. Distribuição de resultados de classificação das escolas, agrupados em blocos, de acordo com o atendimento aos requisitos sanitários normativos ${ }^{9}$.

\begin{tabular}{|c|c|c|c|c|c|c|c|c|c|c|c|c|c|c|c|c|c|c|}
\hline \multirow{2}{*}{$\begin{array}{l}\text { Classifi- } \\
\text { cação } \\
(\%)\end{array}$} & \multicolumn{2}{|c|}{ Edificação } & \multicolumn{2}{|c|}{ Higienização } & \multicolumn{2}{|c|}{$\begin{array}{c}\text { Vetores de } \\
\text { pragas } \\
\end{array}$} & \multicolumn{2}{|c|}{ Água } & \multicolumn{2}{|c|}{$\begin{array}{c}\text { Menejo de } \\
\text { resíduos }\end{array}$} & \multicolumn{2}{|c|}{ Manipulador } & \multicolumn{2}{|c|}{$\begin{array}{l}\text { Matéria- } \\
\text {-prima }\end{array}$} & \multicolumn{2}{|c|}{$\begin{array}{l}\text { Preparo de } \\
\text { alimentos }\end{array}$} & \multicolumn{2}{|c|}{$\begin{array}{c}\text { Exposição dos } \\
\text { alimentos }\end{array}$} \\
\hline & $n$ & $\%$ & $n$ & $\%$ & $n$ & $\%$ & $n$ & $\%$ & $n$ & $\%$ & $n$ & $\%$ & $n$ & $\%$ & $n$ & $\%$ & $n$ & $\%$ \\
\hline$<30$ & 5 & 2,1 & 1 & 0,4 & 67 & 28,5 & 48 & 20,4 & 12 & 5,1 & 43 & 18,3 & 4 & 1,7 & ד & 14,5 & 37 & 15,7 \\
\hline 31 a 49 & 132 & 56,2 & 63 & 26,8 & 67 & 28,5 & 150 & 63,8 & 72 & 30,6 & 88 & 37,4 & 34 & 14,5 & 181 & 77,0 & 88 & 37,5 \\
\hline 50 a 69 & 98 & 41,7 & 129 & 54,9 & 44 & 18,7 & 37 & 15,8 & 83 & 35,3 & 76 & 32,3 & 122 & 51,9 & 20 & 8,5 & 90 & 38,3 \\
\hline 70 a 89 & 0 & 0 & 36 & 15,3 & 11 & 4,7 & 0 & 0 & 56 & 23,8 & 27 & 11,5 & 74 & 31,5 & 0 & 0 & 19 & 8,1 \\
\hline$>90$ & 0 & 0 & 6 & 2,6 & 46 & 0 & 0 & 0 & 12 & 5,1 & 1 & 0,4 & 1 & 0,4 & 0 & 0 & 1 & 0,4 \\
\hline Total & 35 & 100,0 & 235 & 0,0 & 235 & 0 & 0 & 0 & 235 & 100,0 & 235 & 100,0 & 235 & 100,0 & 235 & 100,0 & 235 & 100,0 \\
\hline
\end{tabular}


806 | R.C.V. CARDOSO et al.

de Goiás ${ }^{7}$ e do Rio de Janeiro ${ }^{5}$, e em escolas estaduais de Poços de Caldas (MG) ${ }^{6}$, o que faz pensar sobre a amplitude da inadequação das instalações físicas das escolas que atendem ao PNAE.

Nas unidades visitadas, 63,0\% dos móveis e $68,9 \%$ dos equipamentos se encontravam em estado de conservação precário, e em $77,0 \%$ das unidades não era realizada a manutenção periódica dos equipamentos, condições também descritas por Mira ${ }^{5}$ e Silva et al. ${ }^{4}$.

Outra condição que contribuiu negativamente para o atendimento à legislação referiu-se às instalações sanitárias. Evidenciou-se que $79,6 \%$ das unidades visitadas não dispunham de banheiros próprios para os funcionários do serviço de alimentação: as instalações sanitárias utilizadas eram de uso compartilhado com os estudantes. Em mais de 90,0\% delas, os banheiros não dispunham de sabonete líquido inodoro $(93,6 \%)$, produto antisséptico $(97,4 \%)$ e toalha de papel não reciclado (92,8\%); em 77,9\% dos banheiros não havia coletores de lixo dotados de tampa (77,9\%).

Adicionalmente, em mais de $90 \%$ das cantinas não havia, na área de manipulação, lavatório de mãos (96,6\%), sabonete líquido inodoro $(98,3 \%)$, produto antisséptico $(98,7 \%)$, toalha de papel $(97,9 \%)$ e coletor de papel na área de manipulação $(98,3 \%)$.

Nesse cenário, são explicitadas condições estruturais que conduzem à inadequação da higiene pessoal dos manipuladores, fato que constitui uma das principais causas às DVA. Torna-se fundamental, portanto, que as escolas possam proporcionar melhores condições de higiene pessoal a partir de instalações adequadas aos serviços, de modo a viabilizar a obtenção de alimentos mais seguros.

\section{Higienização de instalações, equipamentos, móveis e utensílios}

Entre os aspectos avaliados, chamou a atenção a falta de funcionários específicos para a higienização da área de produção, constatada em $93,2 \%$ das unidades. Esse tipo de serviço era reali- zado, na maioria das vezes, pelo próprio manipulador de alimentos, uma prática que coloca em risco de contaminação o alimento manuseado.

Situação semelhante foi observada por Rezende et al. ${ }^{12}$, em pesquisa realizada com 264 manipuladores de alimentos de 57 escolas públicas da área urbana de Uberlândia (MG), nas quais apenas $25 \%$ do quadro de funcionários eram contratados para exercer a função de manipulador de alimentos e $75 \%$ para outras funções - zelador e serviçal, embora todos manipulassem alimentos para o preparo das refeições dos alunos.

Ainda que $98,3 \%$ das unidades adquirissem produtos para higienização registrados e que $85,5 \%$ dos entrevistados relatassem realizar a sanificação da área de produção, observou-se que critérios de diluição e tempo de contato nos procedimentos não eram seguidos, o que diminui a eficácia da técnica, podendo favorecer o crescimento microbiano. Paralelamente, em 19,1\% das escolas evidenciou-se a falta de materiais para execução das operações de limpeza, como vassouras, rodos, baldes entre outros, enquanto em $17,9 \%$ faltavam produtos para essa finalidade, incluindo detergentes e sanificantes.

Embora seja uma grande fonte de contaminação ${ }^{13}$, o uso de toalhas de pano foi uma prática observada em todas as escolas visitadas. $\mathrm{Na}$ investigação, 63,4\% dos entrevistados afirmaram fazer a troca a cada duas horas e $83,0 \%$ afirmaram que as toalhas eram lavadas e fervidas. Contudo, durante as visitas, não foi possível confirmar as práticas reportadas.

Em $66,8 \%$ das unidades foram encontradas caixas de gordura, todavia 37,9\% delas não passavam por limpeza periódica, o que favorecia o seu enchimento e o retorno dos resíduos, em alguns casos, para a própria área de produção de alimentos, propiciando a disseminação de contaminantes.

\section{Controle de vetores e pragas urbanas}

A existência de pragas em áreas de manipulação de alimentos oferece perigos constantes 
de contaminação, perdas de alimentos e veiculação de doenças, razão pela qual o controle deve ser efetivo, atendendo às recomendações da legislação ${ }^{14}$.

Nesse estudo, constatou-se que pouco mais da metade das escolas $(54,5 \%)$ contavam com procedimentos de desinsetização sistemática e em $46,0 \%$ foram encontrados insetos e vestígios deles na área de produção durante a manipulação dos alimentos. Esse fato pode ser atribuído à presença de lixo e de material em desuso nos arredores, bem como à ausência de barreiras de proteção, irregularidades já mencionadas na avaliação da edificação.

No trabalho conduzido por Piragine ${ }^{10}$, verificou-se que $100,0 \%$ das escolas não adotavam medidas de prevenção, embora houvesse a declaração de presença de animais ou ainda evidência de sua presença em 17,5\% delas.

\section{Abastecimento de água}

Todas as escolas dispunham de água proveniente da rede pública para preparo dos alimentos e higienização, embora em uma escola tivesse sido identificado o uso de água de poço. Todavia, em apenas 31,1\% houve informação quanto ao monitoramento da qualidade da água e em apenas $8,1 \%$ verificou-se o registro de potabilidade da água, certificado emitido pelo órgão público responsável. A irregularidade no suprimento da água foi reportada em $17,4 \%$ dos casos.

Os reservatórios de água eram providos de tampas na maioria das escolas $(92,8 \%)$, contudo em $23 \%$ deles foram constatadas inadequações quanto ao tipo de revestimento ou estado de conservação, o que propicia oportunidades de contaminação da água. De forma mais crítica, em pouco mais da metade das escolas $(54,5 \%)$ houve declaração de higienização periódica.

Dada a descrição, evidencia-se falha grave na gestão da segurança dos alimentos nas escolas, uma vez que a água constitui um dos mais impor- tantes recursos na produção de alimentos, configurando fator decisivo na determinação da sua inocuidade. Nesse caso, além das infrações diante da RDC 216/049 , análises microbiológicas de água das escolas, realizadas posteriormente, registraram não conformidade em $41,0 \%$ das amostras ${ }^{15}$, confirmando a condição de risco observada.

\section{Manejo de resíduos}

Os resultados encontrados nesse bloco registraram a presença de recipientes para lixo em $66,8 \%$ das cantinas, entretanto $60,9 \%$ deles não eram bem conservados, dotados de tampa sem contato manual e providos de sacos plásticos. Condições semelhantes foram verificadas em pesquisa realizada no estado de Goiás ${ }^{7}$, onde 34,9\% das escolas apresentavam lixeiras sem tampas e não conformidade em relação às condições de higiene.

Paralelamente, verificou-se que em $42,6 \%$ das escolas o lixo coletado das cantinas, em cada turno de produção, não era estocado em local isolado. Na maioria das vezes, os resíduos eram levados para o pátio das escolas, dentro de sacos ou sacolas plásticas, e colocados em recipientes impróprios para o acondicionamento, como baldes plásticos e tonéis sem tampas ou caixas de papelão, até o horário da coleta urbana. Notou-se, ainda, que em muitos casos, os resíduos eram depositados em locais próximos às cantinas, procedimento que, além de comprometer a higiene ambiental, expõe os escolares a situações de risco, já que a maioria das crianças faz uso do pátio para recreação e alimentação.

Embora a coleta pública de lixo ocorresse diariamente para a maior parte das escolas, evidenciou-se que em $15,7 \%$ dos casos isso não acontecia, tornando ainda mais grave a questão da higiene ambiental, na medida em que esses resíduos ficavam amontoados, à temperatura ambiente, aumentando as chances de proliferação de pragas e vetores.

Segundo Silva et al. ${ }^{4}$, a presença de insetos e pragas urbanas relaciona-se à falta de higiene, 
808 | R.C.V. CARDOSO et al.

contudo o desconhecimento das medidas preventivas e corretivas do ambiente, a falta de um programa de controle de pragas adequado e estrutura deficiente das edificações também contribuem para a presença desses animais.

\section{Manipuladores de alimentos}

Na epidemiologia das doenças veiculadas por alimentos, tem sido bem caracterizado o papel-chave dos manipuladores de alimentos na disseminação de patógenos. Dada a relevância dessas pessoas para a produção de alimentos seguros, princípios de higiene pessoal e de alimentos devem ser continuamente reforçados e monitorados, sendo essencial a realização de atividades de capacitação ${ }^{11,16}$.

Os resultados nessa avaliação foram bastante preocupantes, pois se evidenciou que em 80,9\% das escolas não era realizada a capacitação semestral dos manipuladores; $90,7 \%$ dessas escolas eram estaduais e 73,9\%, municipais. A falta de capacitação da maioria dos manipuladores das escolas, em parte, justifica alguns valores observados em relação aos hábitos e procedimentos de higiene pessoal que comprometem a segurança dos alimentos, tais como: 49,4\% mantinham unhas longas e com esmalte e/ou sujidades; 70,6\% usavam adornos; 93,2\% não utilizavam sapatos fechados; 66,4\% conversavam, assobiavam ou cantavam durante o preparo dos alimentos; 94,9\% não utilizavam luvas para manipular alimentos prontos para o consumo.

A insuficiência de formação de manipuladores de alimentos no contexto da educação pública tem sido evidenciada em diversas pesquisas $4,5,7,10$. Pistore \& Gelinskib ${ }^{17}$, em trabalho conduzido com $78,57 \%$ dos manipuladores de escolas de Videira (SC), avaliaram, pela aplicação de formulário, o domínio de conhecimentos higiênico-sanitários. No estudo, questões relacionadas a doenças transmitidas por alimentos, saúde, higiene do manipulador de alimentos e higiene das instalações, equipamentos e utensílios foram apresentadas, verificando-se um percentual de erros de $24,5 \%, 23,4 \%$ e $25,4 \%$, respectivamente, o que aponta para a necessidade de capacitação que proporcione aprendizado efetivo e aplicação dos conhecimentos.

Em relação ao uso dos uniformes, 56,2\% dos manipuladores usavam, contudo $23,4 \%$ não eram compatíveis com a atividade e/ou não se encontravam conservados e 31,9\% não eram trocados diariamente e/ou não se apresentavam limpos. Além disso, em 37,9\% das escolas verificou-se que esses funcionários não retiravam o avental ao sair da cantina, inclusive para ir ao banheiro.

Apesar de os manipuladores não utilizarem de forma adequada os uniformes, o mesmo não ocorreu com os protetores de cabelo, que foram identificados em 66,0\% das unidades visitadas. Segundo Silva et al. ${ }^{4}$, o uso desses protetores evita a contaminação física dos alimentos pelos cabelos e impede a disseminação de microrganismos neles presentes.

Os manipuladores de alimentos de 77,0\% das escolas afirmaram lavar as mãos ao chegar ao trabalho, porém em 51,7\% das unidades verificou-se que esses profissionais não realizavam essa prática antes de manipular os alimentos e de tocar em qualquer outro material. A falta de capacitação, de estrutura física e de materiais disponíveis para a adequada higienização das mãos nas escolas visitadas explicam, em parte, os hábitos adotados pelos manipuladores de alimentos no seu local de trabalho, conferindo risco para a saúde dos escolares.

\section{Matérias-primas, ingredientes e embalagens}

Na cadeia produtiva de alimentos, a recepção da matéria-prima é considerada como um ponto de controle. Devido a isso, os cuidados com a seleção de fornecedores e a conferência dos produtos durante o recebimento e o armazenamento constituem exigências legais ${ }^{9}$ que contribuem para a garantia da qualidade e da inocuidade do produto final. 
Merece destaque a inadequação de várias unidades quanto ao local de recepção dos gêneros, uma vez que não dispunham de área reservada $(98,3 \%)$. Ao mesmo tempo, ainda que fosse relatada a verificação da temperatura dos produtos recebidos, em nenhuma delas observou-se a existência de termômetros para essa conferência.

Em $81,7 \%$ dos casos, produtos não perecíveis eram estocados em prateleiras, todavia, em $84,7 \%$ desses, os alimentos não estavam afastados da parede, do solo e/ou do teto, o que facilita o acesso de insetos e alterações da umidade. Essa condição foi ainda mais agravada pela falta de ventilação na área de armazenamento em muitas unidades $(51,7 \%)$, conformando fatores que contribuem sinergicamente para a contaminação da matéria-prima estocada e redução da sua vida útil.

\section{Preparação de alimentos}

Os resultados encontrados nesse bloco constituíram motivo de preocupação, uma vez que foi elevado o percentual de escolas categorizadas nos níveis insatisfatório e crítico.

Observou-se que $96,6 \%$ das cantinas não dispunham de áreas distintas para a manipulação de alimentos crus e cozidos, o que pode contribuir para a contaminação cruzada. Além disso, em $30,2 \%$ dos casos, os produtos perecíveis utilizados para o preparo da alimentação escolar ficavam à temperatura ambiente por período superior ao recomendado9.

Em $86,6 \%$ das unidades, os manipuladores de alimentos afirmaram higienizar os vegetais crus, entretanto, as técnicas relatadas eram distintas e, quando do uso de agentes sanificantes, observou-se o não atendimento aos critérios de diluição e tempo de contato. Mais de $50,0 \%$ lavavam os produtos apenas com água, $20,4 \%$ utilizavam água e vinagre, $24,7 \%$ lavavam com água e sabão, e somente $8,9 \%$ utilizavam água e produto clorado, que seria a técnica de escolha.
Os resultados, além de mostrarem a falta de padronização nos procedimentos de higienização utilizados, revelam risco de proliferação microbiana, posto que a maior parte dos métodos citados têm eficiência mínima na redução de patógenos e parasitas.

Quanto ao item conservação pelo frio, verificou-se que na maioria das escolas $(82,6 \%)$ os alimentos que necessitavam desse tipo de conservação encontravam-se em condições apropriadas de armazenamento.

Falhas na higienização das embalagens dos alimentos, antes de serem abertas para utilização, foram detectadas em 37,0\% das escolas. Das embalagens abertas com conteúdo não utilizado totalmente, $23,8 \%$ não eram guardados em local e de forma adequada; além disso, em 31,5\% das escolas não era registrado o prazo de uso dos produtos já abertos. Dessa forma, é possível que alguns ingredientes utilizados para preparo da alimentação escolar já estivessem com o prazo de validade vencido.

Quanto às práticas de descongelamento de carnes, notou-se que $68,9 \%$ das escolas não procediam da maneira correta, o que também foi verificado em Goiás e em São Paulo ${ }^{18}$. Em grande proporção de escolas de Salvador, o descongelamento era feito à temperatura ambiente, sendo, muitas vezes, as carnes retiradas dos freezers no dia anterior ao preparo, condição que favorece a multiplicação e disseminação microbiana. Em 31,5\% dos casos, verificou-se o recongelamento das carnes, uma prática que envolve tanto riscos de natureza microbiológica quanto perdas nutricionais e sensoriais para o produto.

A dessalga de carnes era conduzida corretamente em $80,4 \%$ das cantinas, entretanto em $12,3 \%$ o procedimento era feito com o uso de água à temperatura ambiente sem trocas periódicas.

Constatou-se ainda que $99,1 \%$ das unidades não eram providas de equipamentos para conservação à quente de alimentos prontos para o consumo, sendo sua manutenção realizada em temperatura ambiente. Felizmente, em 84,3\% das escolas o período entre o preparo e o consumo 
$810 \mid$ R.C.V. CARDOSO et al.

era inferior a duas horas, o que limita as chances de multiplicação e de recontaminação microbiana.

A falta de controle no binômio tempo/temperatura na conservação de alimentos prontos para o consumo na alimentação escolar tem sido reportada em diferentes estudos no Brasil 7,8,18, e constitui uma das principais causas de surtos nos Estados Unidos ${ }^{11}$. Dessa forma, torna-se essencial a adoção de medidas que possam minimizar riscos nessa etapa da produção no âmbito da implementação do PNAE.

Adicionalmente, verificou-se a utilização de artifícios para resfriamento dos alimentos preparados, com uso de ventiladores, o que compromete a segurança dos alimentos pela intensa disseminação de contaminantes, prática que coincide com descrição apresentada por Oliveira et al. ${ }^{18}$, em São Paulo.

\section{Exposição dos alimentos preparados}

No momento de distribuição da alimentação escolar verificou-se que $88,1 \%$ dos manipuladores não faziam antissepsia das mãos antes de servir os alimentos e que $94,3 \%$ não utilizavam luvas.

Em $74,5 \%$ das unidades identificou-se a ausência de refeitórios, sendo os alimentos consumidos no pátio ou na sala de aula. Na primeira situação, avalia-se uma pior condição tanto em relação à proteção dos alimentos - visto os pátios serem, muitas vezes, áreas abertas, sem lavatórios de mãos, com objetos entulhados e animais, o que favorece contaminações, quanto no que se refere à falta de acomodações para as crianças.

No estado do Rio de Janeiro, de modo contrário, Mira ${ }^{5}$ constatou elevado número de escolas que contavam com refeitórios, embora fosse frequente a insuficiência de cadeiras ou de utensílios para atender ao número de refeições.

No presente estudo, em 11,9\% das cantinas observou-se o não descarte das sobras de alimentos expostos durante a distribuição. Nesses casos, os produtos passam a constituir fonte potencial de microrganismos, uma vez que, além de terem permanecido à temperatura ambiente, sofrem abusos na exposição, o que aumenta consideravelmente sua carga contaminante. Como forma de eliminar riscos, a RDC 216/04 ${ }^{9}$ preconiza o descarte de produtos expostos.

Registra-se, por fim, a ocorrência de um surto de DVA em uma escola municipal durante a condução do estudo, embora o levantamento epidemiológico realizado não tenha identificado a fonte da contaminação e o agente causal ${ }^{19}$. Nenhuma das escolas dispunha de Manual de Boas Práticas e o acompanhamento por técnicos de nível superior era insuficiente: cinco nutricionistas da rede municipal para 359 escolas e um nutricionista na rede estadual para 250 escolas da capital, não sendo computadas mais de mil escolas distribuídas no interior do Estado.

\section{CONCLUSÃO}

Mediante os resultados, verifica-se que parte expressiva das unidades avaliadas foi classificada no nível insatisfatório, o que se interpreta como um baixo atendimento aos requisitos normativos. Outra grande parte foi categorizada no nível regular, o que ainda aponta para a necessidade de adequações nos serviços para melhorar a segurança dos alimentos fornecidos pelo PNAE.

$\mathrm{Na}$ avaliação por blocos, os aspectos que mais contribuíram para o baixo desempenho compreenderam aqueles referentes à edificação e às instalações, controle de qualidade da água, manipuladores de alimentos, preparo e exposição dos alimentos, que apresentam impactos diretos e indiretos em relação à inocuidade da alimentação escolar.

Dessa forma, conclui-se que a produção de refeições nas escolas assistidas pelo PNAE em Salvador (BA) não atende a requisitos de segurança de alimentos e envolve riscos à saúde dos beneficiados. Nesse sentido, o estudo indica a necessidade de medidas de intervenção que possam promover e assegurar a qualidade do serviço prestado, com vistas a proteger a saúde das crianças assistidas e cumprir os objetivos do Programa. 


\section{COLABORADORES}

R.C.V. CARDOSO, J.A.W. GÓES, R.C.C. ALMEIDA, A.G. GUIMARÃES e E.O. SILVA participaram da concepção e da implementação do projeto e da redação e revisão final do artigo. D.L. BARRETO, K.V.N.A. FIGUEIREDO, S.A. SILVA, P.O. VIDALJR. e L.B. HUTTNER realizaram coleta de dados em campo e colaboraram na interpretação das informações e na redação do artigo.

\section{REFERÊ N CIAS}

1. Brasil. Presidência da República. Constituição da República Federativa do Brasil 1988. Brasília; 1988 [citado em 2007 jul 14]. Disponível em: <http:// www.planalto.gov.br/ccivil_03/Constituicao/ Constitui\%C3\%A7ao.htm>.

2. Brasil. Ministério da Educação. Fundo Nacional de Desenvolvimento da Educação. Conselho Deliberativo. Resolução/FNDE/CD/N 32 de 10 de agosto de 2006. Estabelece as normas para a execução do Programa Nacional de Alimentação EscolarPNAE. [citado em 2007 nov 23]. Disponível em: <ftp://ftp.fnde.gov.br/web/resolucoes_2006/ res032_10082006.pdf>.

3. Brasil. Ministério da Educação. Fundo Nacional de Desenvolvimento da Educação. Alimentação Escolar. Dados estatísticos. [citado em 2008 jun 2]. Disponível em: <http://www.fnde.gov.br/home/ index.jsp? arquivo=alimentacao_escolar.html\# dadosesta>.

4. Silva C, Germano MIS, Germano PML. Condições higiênico-sanitárias dos locais de preparação da merenda escolar, da rede estadual de ensino em São Paulo, SP. Hig Aliment. 2003; 17(110):49-55.

5. Mira FD. Avaliação do Programa de Alimentação Escolar da Rede Estadual de Ensino do Rio de Janeiro [monografia]. Rio de Janeiro: Universidade Estadual do Rio de Janeiro; 2003.

6. Vieira CRN, Silva RR, Martino HSD, Chavasco JK. Qualidade microbiológica da merenda escolar servida nas escolas estaduais de Poços de Caldas, MG. Hig Aliment. 2005; 19(128):90-4.

7. Goiás. Secretaria de Estado da Saúde. Superintendência de Vigilância Sanitária Universidade Federal de Goiás. Faculdade de Nutrição. Avaliação e monitoramento da qualidade dos alimentos oferecidos na merenda escolar. [Relatório Parcial]. Goiás; 2004.

8. Rosa MS, Negreiros SRF, Seabra LMJ, Stamford TLM. Monitoramento de tempo e temperatura de distribuição de preparações à base de carne em escolas municipais de Natal (RN), Brasil. Rev Nutr. 2008; 21(1):21-8. doi: 10.1590/S1415-5273200800100 003.

9. Brasil. Ministério da Saúde. Agência Nacional de Vigilância Sanitária. Resolução de Diretoria Colegiada $n^{\circ} 216$, de 15 de setembro de 2004. Regulamento técnico de boas práticas para serviços de alimentação. [acesso em 2006 dez 20]. Disponível em: <http://e-legis.bvs.br/leisfef/public/show Act.php?id=12546>.

10. Piragine KO. Aspectos higiênicos e sanitários do preparo da merenda escolar na rede estadual de ensino de Curitiba [dissertação]. Curitiba: Universidade Federal do Paraná; 2005.

11. Daniels NA, Mackinnon L, Rowe SM, Bean NH, Griffin PM, Mead PS. Foodborne disease outbreaks in United States schools. Pedriatr Infect Dis J. 2002; 21(7):623-8.

12. Rezende CHA, Costa-Cruz JM, Gennari-Cardoso ML. Enteroparasitoses em manipuladores de alimentos de escolas públicas em Uberlândia (Minas Gerais), Brasil. Rev Panam Salud Publica. 1997; 2(6): 392-7.

13. Miranda LK, Damasceno KSFSC, Cardonha MAS. Panos de prato e mãos de manipuladores: avaliação das condições higiênico-sanitárias. Hig Aliment. 2002; 16(102):51-8.

14. Hazelwood D, McLean AC. Manual de higiene para manipuladores de alimentos. São Paulo: Varela; 1998.

15. Cardoso RCV, Almeida RCC, Guimarães AG, Goes JAW, Silva AS, Santana AAC, et al. Qualidade da água utilizada em escolas atendidas pelo Programa Nacional de Alimentação Escolar (PNAE), em Salvador-BA. Rev Instituto Adolfo Lutz. 2007; 66(3): 287-91.

16. Germano PML, Germano MLS. Higiene e vigilância sanitária dos alimentos. São Paulo: Varela; 2001.

17. Pistore AR, Gelinskib JMLN. Avaliação dos conhecimentos higiênico-sanitários de manipuladores de merenda escolar: fundamento para treinamento contínuo e adequado. Hig Aliment. 2006; 20(146): 17-20.

18. Oliveira ACB, Germano PM, Germano MIS. Avaliação dos alimentos cárneos servidos no programa de alimentação escolar de um município na grande São Paulo: ênfase nos aspectos tempo-temperatura. Hig Aliment. 2004; 18(124):24-9.

19. Salvador. Secretaria Municipal de Saúde. Subcoordenação de Vigilância Sanitária. Relatório Técnico sobre surto de toxinfecção alimentar em uma unidade escolar. Salvador; 2005.

Recebido em: 23/8/2008

Versão final reapresentada em: 18/5/2009

Aprovado em: 4/5/2010 
